\title{
Exigências do trabalho, prevalência de dor muscular e de sintomas de estresse em estagiários do setor de cobrança de um banco internacional
}

\section{Work demands, prevalence of musculoskeletal pain and stress symptoms on trainees of the collect section of an international bank}

\author{
Débora Miriam Raab Glina ${ }^{1}$ \\ Lys Esther Rocha ${ }^{2}$
}

\begin{abstract}
GLINA, D. M. R.; ROCHA, L. E. Exigências do trabalho, prevalência de dor muscular e de sintomas de estresse em estagiários do setor de cobrança de um banco internacional. Rev. Ter. Ocup. Univ. São Paulo, v. 14, n. 1, p. 10-8, jan./abr., 2003.

RESUMO: Objetivo: compreender exigências do trabalho, prevalência de dor muscular e sintomas de estresse em estagiários do setor de cobrança de um banco internacional, localizado em São Paulo. Método: Análise ergonômica do trabalho, observações globais e sistemáticas, entrevistas com informantes-chave, questionários respondidos voluntariamente pelos estagiários. Resultados: O objetivo do setor era evitar que clientes com potencial se tornassem devedores, bem como, cobrar de clientes devedores. O objetivo era de atender 11000 clientes por mês. A seção trabalhava com teleatendimento receptivo e ativo. Havia 67 estagiários e 5 supervisores. Quase todos estagiários trabalhavam em turnos fixos de $6 \mathrm{~h} / \mathrm{dia}$, com uma pausa de 30 minutos e eles faziam horas-extras. $85 \%$ eram do sexo feminino, $83,7 \%$ possuiam idades entre 18 e 23 anos. Todos tinham pelo menos superior incompleto. $98,6 \%$ eram solteiros, sem filhos. $68,8 \%$ tinham menos de 1 ano de tempo de serviço. $97 \%$ dos estagiários apresentavam sintomas de estresse. Os sintomas mais freqüentes eram: inabilidade de relaxar ou desligar-se do trabalho $(63,0 \%)$, fadiga $(50,7 \%)$, problemas de sono $(41,8 \%)$, irritabilidade $(36,9 \%)$, tensão $(35,4 \%)$, chorar com facilidade $(29,2 \%)$, desanimo $(23,9 \%)$, insonia $(21,5 \%)$, suar sem ter feito esforços físicos e sem que estivesse quente $(21,5 \%)$, tristeza $(20,0 \%)$. Com relação à prevalência de dor muscular 50,7\% afirmaram não ter dor e 49,3\% afirmaram ter. A localização da dor era: coluna $30,3 \%$, ombros $45,5 \%$, pescoço $66,7 \%$, cotovelos $12,1 \%$ e punhos/mãos $30,3 \%$. A relação entre prevalência de dor musculoesquelética e sintomas de estresse era: 50,7\% dos estagiários apresentavam sintomas de estresse mas não dor muscular, $3,0 \%$ dos estagiários apresentavam dor muscular mas não sintomas de estresse, $46,3 \%$ apresentavam dor muscular e sintomas de estresse.
\end{abstract}

DESCRITORES: Trabalho/psicologia. Estresse psicológico. Trabalhadores/classificação. Doenças musculares/patologia. Dor/etiologia.

\footnotetext{
1 Psicóloga do Centro de Referência em Saúde do Trabalhador de Santo Amaro, Secretaria Municipal da Saúde, Prefeitura do Município de São Paulo, professora doutora da Fundação Visconde de Cairu, CEPPEV, Mestrado em Gestão Organizacional e Desenvolvimento Humano, Salvador, Bahia e professora colaboradora do Departamento de Medicina Legal, Ética Médica e Medicina Social e do Trabalho da Faculdade de Medicina da Universidade de São Paulo. e-mail: deboraglina@uol.com.br

2 Professora doutora do Departamento de Medicina Legal, Ética Medical e Medicina Social e do Trabalho da Faculdade de Medicina da Universidade de São Paulo-LIM-40 e médica da Delegacia Regional do Trabalho de São Paulo - Ministério do Trabalho e Emprego. e-mail: lysrocha@usp.br

Endereço para correspondência: Débora M. Raab Glina. Alameda Ribeirão Preto, 438. Ap. 1501. São Paulo, SP. CEP: 01331-000.
} 


\section{INTRODUÇÃO}

$\mathrm{A}$ compreensão do que seja estresse varia para diferentes autores. Selye em 1936 o definiu como: a resposta não específica do corpo a qualquer exigência feita sobre ele, ou seja, um conjunto orquestrado de defesas do corpo contra qualquer forma de estímulo nocivo (estressor). Assim, o estresse designa todos os efeitos não específicos de fatores que podem agir sobre o corpo.

Estresse não é doença e sim tentativa de adaptação. Trata-se de um processo psiconeuroendocrinológico por meio do qual, na presença de ameaças (reais ou imaginárias) serão ativados alguns sistemas do organismo humano, os quais permitirão vários tipos de defesa, como por exemplo, a luta ou fuga. Ele ocorre no dia a dia, faz parte de todas as atividades. Pode ser positivo quando motiva, desafia, possibilita um senso de propósito. Frente a estressores muito intensos ou muito duradouros a capacidade de adaptação pode esgotar-se sobrevindo a doença ou até a morte. Trata-se de um estresse "negativo", o distress. Muitos eventos estressantes (sejam positivos ou negativos) podem causar uma sobrecarga de estresse.

Um segundo ponto a considerar é que os eventos em si não são estressantes. É a forma como interpretamos e reagimos a eles que os torna estressantes. Nem sempre o que é estressor para uma pessoa o será para outra, isto porque somos diferentes em função de nossa história de vida e personalidade e tendemos a interpretar os eventos do cotidiano de forma diferente. Ou seja, o indivíduo não é um ser que responde passivamente a estressores, mas alguém que ativamente interage com eles.

Assim, frente a um estressor potencial nos perguntamos: De que forma isto afeta meu bem-estar? A nossa resposta podendo ser: a) isto pode me causar benefício; b) isto é neutro; ou c) isto pode me causar problemas (mal, perda, ameaça ou desafio). A segunda pergunta é: posso enfrentar esse problema? Se a resposta for positiva colocamos em prática uma ou várias entre milhares de estratégias para enfrentar o problema. Caso contrário, nossas opções diminuem bastante e podem ser totalmente ineficazes para lidar com o estressor. Além disso, nossas avaliações cognitivas e formas de enfrentamento vão se modificando face a novas informações, novos fatos. Nesse contexto, podemos definir estresse seguindo Lazarus e Folkman (1984), para quem estresse é:

a relação particular entre a pessoa e o ambiente, que é avaliada pela pessoa como sobrecarregando ou excedendo seus recursos e ameaçando o seu bemestar
O estresse no trabalho pode ser definido como respostas danosas físicas e emocionais que ocorrem quando exigências do trabalho estão em desacordo com capacidades, recursos ou necessidades do trabalhador, em condições em que o fracasso em atender as exigências tem importantes conseqüências percebidas (NIOSH,1997).

De acordo com NIOSH (1997) a ligação entre fatores psicossociais relacionados ao trabalho e os distúrbios ósteomusculares é complexa e multifatorial. Características pessoais e situacionais podem levar a diferenças na forma com que trabalhadores expostos ao mesmo trabalho e ambiente de trabalho percebem e/ ou reagem à situação. Existem quatro tipos plausíveis de explicações sugeridas para dar conta das associações entre fatores psicossociais e distúrbios ósteomusculares: 1) as demandas psicossociais podem produzir aumento da tensão muscular e exacerbar a tensão biomecânica relacionada à tarefa; 2) as exigências psicossociais podem afetar a consciência dos sintomas ósteomusculares e seu relato e/ou percepções de sua causa; 3) episódios iniciais de dor baseados em danos físicos podem desencadear uma disfunção crônica do sistema nervoso, fisiológica, bem como psicológica, que perpetua o processo de dor crônica; 4) mudanças nas exigências psicossociais podem estar associadas com exigências físicas e biomecânicas, como consequiência, associações entre exigências psicossociais e distúrbios ósteomusculares ocorrem através de uma relação causal ou modificadora de efeito.

Segundo Couto et al. (1998) o organismo pode ficar hipersusceptível às lesões caso esteja excessivamente tenso. Quando o nível de tensão se torna excessivo, o indivíduo passa a sofrer e a principal área de sofrimento é o seu sistema músculo esquelético porque

ao estarem tensos, os músculos recebem um menor suprimento de oxigênio, passam a trabalhar em algum grau de anerobiose e passam a ter uma produção interna de ácido lático, substância sabidamente irritante das terminações nervosas de dor (COUTO, 1998, 1995).

Portanto, ao compreender e atuar sobre a questão do estresse em centrais de atendimento a cliente é possível prevenir enfermidades relacionadas ao estresse, incluindo os Distúrbios Ósteomusculares Relacionados ao Trabalho (DORT).

Os "call centers" ou centrais de atendimento telefônico dizem respeito a qualquer atividade por meio de sistemas de informação e múltiplas mídias, com o objetivo de desenvolver ações padronizadas e contínuas de marketing ou favorecer a comunicação com clientes, 
público ou agências governamentais. Trata-se de usar os sistemas de telefonia, informática e dados.

Os "call centers" são cada vez mais comuns em empresas de vários ramos de atividade: indústria, comércio, prestação de serviços e financeiras. Para Toomingas et al. (2001), a central de atendimento é, talvez, o setor do mercado de trabalho que mais cresce atualmente. Existem, segundo estimativas, em torno de cinco milhões de pessoas empregadas em centrais de atendimento nos Estados Unidos e, aproximadamente, um milhão e meio na Europa. No Brasil, de acordo com o Sindicato de telemarketing (2001) o número de "call centers" cresceu 30\% nos últimos 20 anos. Estimativas apontam para a existência de 284 mil operadores no país e 120 mil apenas no Estado de São Paulo. Entre as atividades das centrais de atendimento encontra-se a cobrança por teleatendimento.

Entretanto, apesar do crescimento do número de centrais de atendimento telefônico, não houve uma proporcional atualização dos processos de projeto e planejamento organizacional nestes novos ambientes de trabalho, o que ocasionou um aumento da rotatividade, absenteísmo e doenças ocupacionais (FERREIRA et al., 1997).

O objetivo deste estudo foi compreender as exigências do trabalho dos estagiários do Setor de Cobrança de um Banco internacional e conhecer a prevalência de DORT e de sintomas de estresse.

\section{MÉTODOS E PROCEDIMENTOS}

Foi realizada a Análise Ergonômica do Trabalho dos estagiários de cobrança e dos supervisores. Ergonomia é o conhecimento sobre o homem em atividade, visando aplica-lo à concepção de tarefas, de instrumentos, de máquinas e de sistemas de produção (LAVILLE, 1976).

A pesquisa ergonômica pura tradicional, de acordo com Westlander (1996) considera o modo com que equipamento e pessoas estão adaptados uns aos outros no trabalho. Mas existem também enfoques ergonômicos mais amplos nos quais a análise se estende para levar em conta a situação de trabalho na qual o equipamento é utilizado. Assim, são considerados fatores da organização e o conteúdo do trabalho, bem como certos fenômenos organizacionais tais como, as políticas de recursos humanos.

A Ergonomia Francesa tem um enfoque mais amplo. A Ergonomia Francesa volta-se mais aos estudos de campo, analisa as situações reais de trabalho, estuda a situação de homem-atividade. Ela leva em conta a diversidade e variabilidade das pessoas e das situações (WISNER, 1987).

Neste estudo foram utilizadas as seguintes técnicas: observações globais do setor, observações no posto de trabalho, entrevistas individuais e grupais com informantes-chave (gerente, supervisores e estagiários), aplicação de questionários e análise documental.

As observações globais envolveram o setor como um todo: o crédito, a cobrança, as diferentes localizações espaciais. As observações nos postos de trabalho ocorreram em diversos horários, nas várias ilhas, incluíram ouvir as conversas telefônicas como "carona", observar a atividade, os meios utilizados e as comunicações com outros funcionários. Houve também monitoração eletrônica das ligações, ou seja, escuta das mesmas a partir da mesa dos supervisores.

As entrevistas com o gerente e supervisores foram semi-estruturadas e tiveram por finalidade conhecer a estrutura organizacional do banco, os objetivos do setor, os cargos e número de funcionários em cada cargo, o fluxograma do processo de trabalho, os produtos e serviços oferecidos pelo banco, a descrição da tarefa dos operadores e supervisores, a forma de realização da monitorização, as políticas e práticas de pessoal, os incidentes críticos mais comuns. $\mathrm{O}$ gerente do setor e os 5 supervisores foram entrevistados.

As entrevistas com os estagiários foram semiestruturadas e visaram obter uma descrição da tarefa; levantar as exigências e constrangimentos relacionados ao posto de trabalho (mobiliário, equipamentos, instrumentos, sistema), as condições de trabalho, a organização do trabalho, os relacionamentos (colegas, chefia, clientes e outros setores) e as políticas de pessoal; os aspectos positivos e negativos do trabalho; o que poderia causar danos à saúde; as sugestões para melhorar o trabalho; os incidentes críticos mais comuns. Foram entrevistados 12 estagiários, sendo 3 por ilha.

Foram feitas 25 entrevistas em total. Uma análise de conteúdo das entrevistas foi realizada.

Os questionários respondidos voluntariamente pelos estagiários e supervisores que estavam em atividade, totalizando 67, abrangeram os seguintes aspectos: dados demográficos, descrição da tarefa, características percebidas do trabalho (monotonia, rapidez, controle sobre o próprio trabalho, apoio recebido de colegas e chefia, possibilidade de aprendizado, possibilidade de causar estresse), características percebidas das condições de trabalho, sintomas de estresse. 
A aplicação de questionário ocorreu no local de trabalho, na época em que estavam sendo realizadas as observações. Eles foram auto - preenchidos, houve supervisão durante a aplicação e posterior conferência deles. O tempo médio de preenchimento foi de 20 minutos. A análise dos questionários iniciou-se com a digitação e codificação dos dados. Foi realizada uma análise descritiva, incluindo freqüências simples e porcentagens dos aspectos mais importantes.

O questionário foi testado em outro setor do Banco, com a aplicação para 10 operadores, sendo modificado conforme sugestões.

A análise documental foi realizada em impressos de monitoração, impressos da classificação dos estagiários e em um questionário sobre a forma vigente de avaliação de desempenho elaborado e aplicado pelos supervisores nos estagiários, visando captar as percepções destes a respeito da mesma.

Foram realizados 2 encontros com os estagiários e supervisores, um de manhã e o outro de tarde, para validação e complementação dos resultados.

No total ocorreram 20 visitas ao setor de cobrança, com duração média de 6 horas, em diferentes horários para a coleta dos dados.

Todos os participantes assinaram termo de consentimento livre e participaram voluntariamente da pesquisa.

Trata-se de um estudo basicamente qualitativo, não representativo no sentido estatístico do termo, mas cuja significação é alcançada através da diversificação das situações vivenciadas pelos operadores priorizando a escolha dos sujeitos e situações que permitam uma aproximação do fenômeno estudado (MINAYO, 1993). Segundo Minayo (1993) em pesquisas qualitativas existe uma preocupação menor com a generalização e maior com o aprofundamento e abrangência da compreensão seja de um grupo social, de uma organização, de uma política ou de uma representação, motivo pelo qual o critério de amostragem não é numérico.

\section{RESULTADOS}

As características dos estagiários estão retratadas na Tabela 1: $85,1 \%$ pertencem ao sexo feminino e 83,7\% apresentam idades entre 18 e 23 anos; todos possuem no mínimo nível superior incompleto; $98,6 \%$ são solteiros e sem filhos; $68,8 \%$ estão há menos de um ano na função e até 2 anos, temos $91,2 \%$ dos estagiários.
Tabela 1 - Distribuição dos estagiários do setor de cobrança de um Banco Internacional de São Paulo segundo gênero, faixa etária, presença de filhos e tempo na função

\begin{tabular}{lll}
\hline Características & $\mathbf{N}$ & $\%$ \\
\hline Sexo (n=67) & & \\
Masculino & 10 & 14,9 \\
Feminino & 57 & 85,1 \\
\hline Faixa Etária (n=66) & & \\
18-23 anos & 56 & 84,7 \\
24-29 anos & 9 & 13,6 \\
$30-34$ anos & 1 & 1,7 \\
\hline Presença de Filhos $(\mathrm{n}=67)$ & & \\
Com filhos & 1 & 1,4 \\
Sem filhos & 66 & 99,6 \\
\hline Tempo na Função $(\mathrm{n}=67)$ & & \\
$<1$ ano & 46 & 68,8 \\
$1-2$ anos & 15 & 22,4 \\
2 - 3 anos & 1 & 1,4 \\
$3-4$ anos & 4 & 6,0 \\
$>$ ou = 5 anos & 1 & 1,4 \\
\hline
\end{tabular}

\section{O trabalho dos estagiários}

O setor pertence ao Departamento de Crédito e Cobrança, diretamente ligado à vice-presidência de um Banco Internacional localizado na cidade de São Paulo. Tem por objetivos evitar que clientes com alto potencial de risco de inadimplência se tornem devedores e cobrar clientes devedores. A meta é de 11000 clientes atendidos por mês. Trabalha com teleatendimento receptivo e ativo. $\mathrm{O}$ teleatendimento ativo caracterizase pela realização de chamadas de iniciativa do teleatendente, servindo um programa de visita telefônica que pode ser de venda ao consumidor ou de "clivagem", que implica um relacionamento empresa a empresa no qual o sistema de televendas visa suprir demandas, controlando por telefone as carências de produtos e os serviços das organizações abordadas, como, por exemplo, o Serviço de Apoio ao Cliente (SAC). No teleatendimento receptivo as ligações são de iniciativa do cliente, cabendo ao operador prestar o serviço solicitado.

Conta para o atendimento de seus objetivos, com 67 estagiários e 5 supervisores. Existem 4 ilhas, cumprindo finalidades distintas: lidam com diferentes faixas de atraso, diversos produtos, pessoa física e jurídica. As atribuições dos estagiários e dos supervisores variam de acordo com a ilha. De forma geral, os estagiários devem informar débito, valores, 
cálculos, quitação e obter promessa de pagamento; ao passo que os supervisores montam estratégias de cobrança, fornecem suporte para a equipe, monitoram os estagiários, atendem clientes problemáticos, gerência, agências, unidades de crédito/cobrança e outros setores do Banco. A maior parte dos estagiários trabalha 6 horas diárias, em turnos fixos: 9 a 15 horas e 15 a 21 horas com pausa de 30 minutos e fazem horas extras (trabalham 1 sábado por mês).

Na Ilha M. o objetivo é trabalhar com faixas de atraso menores (early buckets), fazendo com que o cliente pague o mais rápido possível. Os produtos são: conta corrente, financiamento de veículos, empréstimos de curto prazo, empréstimos a empresas de longo prazo, acordos. A Ilha M. possui 10 linhas receptivo (inbound) e 60 linhas ativo (outbound). Os estagiários informam débito, valores, cálculos e quitação e tentar agendar pagamentos e procuram obter promessas de pagamento. Não há autonomia para desconto e negociação. As metas dos estagiários são diferenciadas. $\mathrm{O}$ estagiário ativo desta ilha deve obter 6 a 7 promessas por hora, 30 promessas por dia, tempo médio de atendimento (TMA) de 60 a 70 segundos. O estagiário receptivo deve respeitar um TMA de 140 a 160 segundos, tempo entre ligações 10 a 15 segundos. São 35 estagiários sendo 14 de manhã e 21 à tarde.

A ilha R. trabalha com a cobrança de recuperação de produtos variados, late buckets. A cobrança de recuperação ocorre com os clientes cujos nomes já foram encaminhados para escritórios de advocacia e considerados sem possibilidade de recebimentos pelo Banco. Nesses casos, são oferecidos descontos de 50 a $80 \%$ para quitação da dívida, visando a recuperação de dinheiro. São feitos acordos, através de parcelamento de dívidas de conta corrente, empréstimos e financiamentos. As metas são em valores. Há 9 estagiários, sendo 2 em período integral ( 9 às $18 \mathrm{~h}$, com $1 \mathrm{~h}$ almoço) e 7 com jornada de 6 horas e meia hora de pausa (9 às $15 \mathrm{~h}$ e 15 às $21 \mathrm{~h}$ ). As atribuições deles são: cobrar clientes com dívidas acima de 90 dias e negociar pagamento. Atendem 20 clientes por dia, pois é difícil achá-los.

A ilha P. trabalha com pessoas jurídicas e faixas de atraso maiores $\left(4^{\circ}, 5^{\circ}\right.$ e $6^{\circ}$ buckets $)$, ou seja, clientes com potencial para serem prejuízo para o Banco. Há 13 estagiários e 2 contratados, sendo 2 estagiários com jornada de 8 horas e 11 com jornada de 6 horas e meia hora de pausa. Em 1999 houve 28,7 milhões de dólares de dívidas, a meta para 2000 era de 18 milhões de dólares. O trabalho consiste em cobrar pessoa jurídica, contatar empresa, explicar débitos.

Existe ainda o atendimento pessoal, cujo objetivo é atender às necessidades dos clientes que comparecem pessoalmente para pagar dívidas. A ilha funciona das 9 às 17 horas. O cliente chega, pega uma senha e aguarda atendimento. Há 5 estagiários (horário de trabalho das 9 às 18 horas, com 1 hora de almoço). Trabalham 2 vezes por mês aos sábados das 9 às 12 horas. Há picos de trabalho entre as 12 e 13 horas. Os estagiários renegociam a dívida, recebem pagamentos de clientes pertencentes a faixa de atraso alta, levam o cliente a entrega amigável de bem (automóvel), recebem pagamento de "leasing" em dólar; inputam acordos, preenchem contratos e notas promissórias, levam para o supervisor para abonar assinatura, levam para crédito aprovar. Em dias fracos atendem de 15 a 20 clientes, nos dias cheios de 25 a 30 clientes, quando há acordo de 10 a 15 clientes. As metas são: número de clientes (o número de senhas não pode estar abaixo de $25 \%$ da média estabelecida), número de acordos, pesquisas de qualidade em $30 \%$ dos clientes. Aqui os estagiários não são monitorados.

\section{Exigências do trabalho e fatores de estresse no trabalho em cada ilha}

Na Ilha M. segundo os estagiários o trabalho é mecânico, repetitivo, não permite o uso de habilidades e potencial, ao mesmo tempo, apresenta muitas informações para memorizar e diversos tipos de situações para lidar. O trabalho é sentado $95 \%$ do tempo, com digitação e atendimento telefônico a clientes. Há restrições temporais e pressão por produtividade (número de promessas de pagamento obtidas, valor envolvido em cada promessa).

Foram referidos os seguintes fatores de estresse: clientes que xingam, irritados, não se conformam que devem; sistema CACS não disponível de manhã; sistema de discagem com problemas, pois volta ligação no dia seguinte ao que falou com o cliente e ele já disse que vai pagar; ser avaliado pelo tempo (TMA), pois cada caso é um caso e às vezes são necessários cálculos; temperatura fria; os estagiários referem que esquecem conteúdos que aprenderam no treinamento; comem muito rápido no almoço; quando pegam um cliente complicado atrás do outro acham que não estão rendendo; se não conseguem atingir as metas do dia ficam irritados, porque não depende apenas deles, não acham válido que as monitorações funcionem como avaliação de desempenho (AD), pois cada monitor tem um critério, o que causa ambigüidade no "feedback" e às vezes não existe concordância do estagiário com o critério de alguns; serem avaliados pelas promessas e 
não pelas "bombas" que pegam, terem de ir a outro computador para pegar o valor de"leasing".

As exigências do trabalho são semelhantes nas ilhas R. e P., mas não há pressão de tempo e são exigidas maiores habilidades de negociação. Os fatores de estresse na Ilha R são: local apertado (nos corredores entre filas de cabines); ruído excessivo; temperatura fria; não concordam com a monitoração; discussão com clientes; digitar demais; estresse por causa da avaliação de desempenho e premiação. Os fatores de estresse na Ilha P são: acesso às informações às vezes um pouco lento; ruído; temperatura fria; não tem atualização on line (ex.: o cliente ter pago parcela e no sistema não ter baixado, depósito que não consta no sistema); fiação descoberta embaixo da mesa, tensão na relação com o cliente; AD estressa, pressão pelas metas, digita-se demais.

Os fatores de estresse no atendimento pessoal são: salas apertadas, sistema precário, deveria haver espaço para 2 cadeiras de cliente em cada sala; não conseguem entrar com a senha no sistema; iluminação fraca; ruído; temperatura fria; clientes na maioria endividados e estressados, questionam taxas de juros, gritam, descontam nelas; carpete (alergia); falta de segurança (perigo de agressão quando o cliente se exalta); sistema trabalhoso quando o cliente tem muitos contratos (produtos), falta de autonomia: o supervisor acaba cedendo e passa por cima do que falaram; deveria haver senha eletrônica; serem estagiários e não funcionários.

As condições de trabalho mostraram níveis elevados de ruído ambiental, baixa temperatura (em decorrência do ajuste do ar condicionado), iluminação insuficiente e com presença de reflexos nas telas, espaço limitado de circulação, estações de trabalho apertadas e em mau estado, problemas com o sistema, com a qualidade das chamadas, com os headsets e com o acesso a informações atualizadas sobre os clientes.

\section{Sintomas de estresse e dor muscular relacionada ao trabalho nos estagiários}

Noventa e sete por cento dos estagiários referiram sintomas de estresse, conforme mostra a Tabela 2. Podiam ser preenchidos vários sintomas de estresse. Os sintomas de estresse que apareceram com maior frequiência foram: não conseguir desligar-se, relaxar $(63,0 \%)$, cansaço $(50,7 \%)$, dificuldades de sono $(41,8 \%)$, irritabilidade $(36,9 \%)$, tensão $(35,4 \%)$, choroso $(29,2 \%)$, desesperança $(23,9 \%)$, insônia $(21,5 \%)$, suar sem fazer esforço e quando não está calor $(21,5 \%)$, tristeza $(20,0 \%)$.
Tabela 2 - Prevalência de sintomas de estresse identificados pelos estagiários do setor de cobrança de um banco internacional de São Paulo

\begin{tabular}{lll}
\hline Sintomas de estresse $(\mathbf{n}=\mathbf{6 7})$ & $\mathbf{N}$ & $\mathbf{\%}$ \\
\hline Não conseguir desligar-se ou relaxar & 41 & 63,0 \\
Cansaço & 34 & 50,7 \\
Dificuldades de sono & 28 & 41,8 \\
Irritabilidade & 24 & 36,9 \\
Tensão & 23 & 35,4 \\
Choro fácil & 19 & 29,2 \\
Desesperança & 16 & 23,9 \\
Insônia & 14 & 21,5 \\
Suar sem esforço e sem calor & 14 & 21,5 \\
Infeliz & 13 & 20,0 \\
Tontura/náuseas & 11 & 16,9 \\
Indigestão & 11 & 16,9 \\
Deprimido & 11 & 16,9 \\
Sentir-se encurralado & 10 & 15,4 \\
Falta de apetite & 8 & 12,3 \\
Dificuldade de concentração & 8 & 12,3 \\
Palpitações & 7 & 10,8 \\
Falta de entusiasmo & 5 & 7,6 \\
\hline
\end{tabular}

A Tabela 3 mostra a prevalência de dor muscular relacionada ao trabalho. 50,7\% dos estagiários não apresentam dor e 49,3\% apresentam. A localização que aparece com maior freqüência é a nuca/pescoço $(66,7 \%)$, seguida dos ombros $(45,5 \%)$.

Tabela 3 - Prevalência de dor muscular relacionada ao trabalho em estagiários do setor de cobrança de um banco internacional de São Paulo e localização da dor

\begin{tabular}{lll}
\hline Prevalência de dor & $\mathrm{N}$ & $\%$ \\
$\begin{array}{l}\text { Presença de dor músculo- } \\
\text { esquelética }(\mathrm{n}=67)\end{array}$ & & \\
\hline Não & 34 & 50,7 \\
Sim & 33 & 49,3 \\
\hline Localização da dor & & \\
músculo-esquelética $(\mathrm{n}=33)$ & & \\
\hline Nuca e pescoço & 22 & 66,7 \\
Ombros & 15 & 45,5 \\
Punhos/mãos & 10 & 30,3 \\
Coluna & 10 & 30,3 \\
Cotovelo & 4 & 12,1 \\
\hline
\end{tabular}

Quanto à relação entre a prevalência de dor muscular relacionada ao trabalho e sintomas de extresse, $50,7 \%$ apresentaram sintomas de estresse, mas não dor músculo esquelética, $46,3 \%$ apresentaram sintomas de estresse e dor músculoesquelética (Tabela 4). 
Tabela 4 - Relação entre a prevalência de dor muscular relacionada ao trabalho e sintomas de estresse em estagiários do setor de cobrança de um banco internacional de São Paulo

\begin{tabular}{|c|c|c|}
\hline Relação $(n=67)$ & $\mathbf{N}$ & $\%$ \\
\hline Apresentou só sintomas de estresse & 34 & 50,7 \\
\hline Apresentou só dor músculo-esquelética & 2 & 3,0 \\
\hline $\begin{array}{l}\text { Apresentou sintomas de estresse e } \\
\text { dor músculo-esquelética }\end{array}$ & 31 & 46,3 \\
\hline
\end{tabular}

\section{DISCUSSÃO}

Os critérios de seleção com a contratação de pessoas muito jovens, muitas das quais em seu primeiro emprego, está associado ao nível das exigências do trabalho. Wisner (1987) afirma que trabalhadores jovens são encontrados em trabalhos que possuam elevadas demandas mentais e físicas. No estudo de um "call center" na Grã Bretanha encontrou-se operadores e gerentes jovens, usualmente abaixo de 35 anos, e eles trabalhavam no "call center" por um curto período de tempo (menos de 2 anos) (AUSTIN KNIGHT; CALCOM GROUP, 1997). Sznelwar e Masseti (2002) também encontraram uma população jovem (entre $20 \mathrm{e}$ 30 anos) no seu estudo com trabalhadores do ramo de serviços que utilizavam sistemas informatizados. Trabalhadores estes que estavam trabalhando há poucos anos e cuja expressão do sofrimento tinha iniciado com apenas 6 meses de trabalho. Muitos desses trabalhadores consideravam esse tipo de trabalho como temporário, entretanto, não havia facilidade para encontrar emprego na sua profissão e, além disso, uma quantidade expressiva deles ficava doente em pouco tempo. No presente estudo também $84,7 \%$ dos trabalhadores tinham até 23 anos e 91,2\% tinham até 2 anos de tempo na função.

Diversos estudos indicaram que várias fontes de estresse no trabalho, tais como, organização do trabalho, medo de perder o emprego, altas demandas do trabalho e falta de controle sobre o trabalho estão relacionadas com a presença e/ou exacerbação de sintomas dos membros superiores relacionados ao trabalho (LEINO, 1989; VASSELJEN; WESTGAARD, 1995; SAUTER; SWANSON, 1996; SMITH; CARAYON, 1996). Cooper e Marshall (1976) listam 6 grandes estressores no trabalho: fatores intrínsecos ao cargo; papel na organização, desenvolvimento da carreira; relacionamentos no trabalho; estrutura e clima organizacional; e fatores extraorganizacionais. Smith et al. (1992) propõem que se inclua o monitoramento eletrônico nessa lista.

Glina e Rocha (2003) encontraram os seguintes fatores de estresse no trabalho de operadores de teleatendimento de um banco: a rapidez em conflito com a qualidade; a grande densidade do trabalho, com grande volume de informações a memorizar; a fila de espera de clientes; a repetitividade da tarefa em contraste com a sua complexidade; a falta de controle sobre o trabalho; a relação difícil e ameaçadora com clientes; as condições de trabalho percebidas como fonte de estresse.

Theorell (1996) mostra que a combinação de elevados graus de exigência e pouco controle sobre o trabalho caracteriza uma situação de estresse, podendo evoluir para uma desordem músculo esquelética.

Faucett e Rempel (1994) evidenciaram que a combinação dos fatores ergonômicos, com a sobrecarga no trabalho e o estresse no trabalho representa importante papel nos sintomas de mãos/punhos e ombros/pescoço de operadores de terminais de vídeo. Modelos recentes descreveram como o estresse no trabalho e os fatores ergonômicos podem interagir contribuindo para sintomas das extremidades superiores relacionados ao trabalho, distúrbios e incapacidade (FEUERSTEIN, 1996; SAUTER; SWANSON, 1996).

A prevalência de sintomas nos ombros foi maior que a registrada por Hales et al. (1994) que verificaram a prevalência de $22 \%$ para trabalhadores de empresa telefônica com função de auxílio a lista. Para estes autores os fatores associados aos sintomas dos ombros e pescoço incluíram o medo de ser substituído por computadores, aumento de pressão no trabalho, aumento da carga de trabalho, rotina de trabalho com poucas oportunidades de tomada de decisões e alta demanda de processamento de informações.

Por outro lado a prevalência verificada foi menor do que a obtida por Hoekstra et al. (1995) de $68 \%$ em duas centrais de atendimentos de uma administradora de seguros. Para estes autores os fatores associados foram: uso do telefone por mais de 8 horas diárias, as posturas desconfortáveis pelo mobiliário e a percepção da falta de controle sobre o trabalho.

Em relação aos limites deste estudo indicamos que a análise da situação de trabalho foi feita em apenas uma central de atendimento telefônico sendo importante a análise de centrais de atendimento telefônico de empresas de diferentes ramos de atividade econômica. Outras limitações do estudo referem-se ao seu desenho transversal, e ser baseado apenas em sintomas sem exame físico dos trabalhadores. 


\section{CONCLUSÃO}

Uma população extremamente jovem, em sua maioria apresentou sintomas de estresse. Dentre os fatores de estresse de maior peso estava a natureza do trabalho; o sistema de avaliação de desempenho e premiação e o relacionamento com os clientes. As más condições de trabalho são um importante fator tanto para a dor muscular quanto para os sintomas de estresse. O aparecimento desses sintomas e da dor ocorreu após pouco tempo de trabalho.

GLINA, D. M. R.; ROCHA, L. E. Work demands, prevalence of musculoskeletal pain and stress symptoms on trainees of the collect section of an international bank . Rev. Ter. Ocup. Univ. São Paulo, v. 14, n. 1, p. 10-8, jan./abr., 2003.

\begin{abstract}
Objective: to understand work demands, prevalence of musculoskeletal pain and stress symptoms on trainees of the collect section of an international bank, located in São Paulo. Methods: Ergonomic work analysis, global and systematic observations, interviews with supervisors, manager and trainees, questionnaires answered voluntarily by the trainees. Results: The objective of the collect section was to avoid that clients with high risk became debtors, as well as to collect from clients who owe the bank money. The aim was 11000 clients attended monthly. The section worked with receptive and active telemarketing. There were 67 trainees and 5 supervisors. Almost all the trainees worked in fixed shifts of 6 hours daily, with one break of 30 minutes and they did overtime. $85 \%$ were female, $83,7 \%$ had ages ranging from 18 and 23 years. All of them were at least college students. $98,6 \%$ were single, without children. $68,8 \%$ had less than one year on the job. $97 \%$ of the trainees showed stress symptoms. The most frequent symptoms were: inability to relax or detach from work $(63,0 \%)$, fatigue $(50,7 \%)$, sleep disorders $(41,8 \%)$, irritability $(36,9 \%)$, strain $(35,4 \%)$, cry easily $(29,2 \%)$, hopelessness $(23,9 \%)$, imnsonia $(21,5 \%)$, to sweat without making physical efforts or when it was not hot $(21,5 \%)$, sadness $(20,0 \%)$. Concerning the prevalence of musculoskeletal pain $50,7 \%$ reported not having and $49,3 \%$ reported having. The location of the pain was: back pain $30,3 \%$, shoulders $45,5 \%$, neck $66,7 \%$, elbows $12,1 \%$ and wrist/hands $30,3 \%$. The relationship between the prevalence of musculoskeletal pain and stress symptoms was: trainees who had stress symptoms but not musculoskeletal pain 50,7\%, trainees who had musculoskeletal pain but not stress symptoms $3,0 \%$, trainees who had both stress symptoms and musculoskeletal pain $46,3 \%$.
\end{abstract}

KEYWORDS: Work/psychology. Stress/psychological. Workes/classification. Muscular diseases/ pathology. Pain/etiology.

\title{
REFERÊNCIAS
}

\section{AUSTIN, K.; CALCOM GROUP. The first national survey of a call center management and staff attitudes. London: Austin Knight UK Limited, 1997.}

COOPER; MARSHALL. Occupational sources of stress: a review of literature relating to coronary heart disease and mental ill health. J. Occup. Psychol., v. 49, p. 11-28, 1976.

COUTO, H. A.; NICOLETTI, S. J., LECH et al. Como gerenciar a questão LER/DORT. Belo Horizonte: Ergo Editora, 1998

FAUCETT, J; REMPEL, D. VDT-related musculoskeletal symptoms: interactions between work posture and psychosocial work factors. Am. J. Ind. Med., v. 26, p. 597 612, 1994

FERREIRA Jr., M.; CONCEIÇÃO, G. M. S.; SALDIVA, P. $\mathrm{H}$. N. Work organization is significantly associated with upper extremities musculoskeletal disorders among employees engaged interactive computer-telephone tasks of an International Bank subsidiary in São Paulo, Brazil. Am. J. Ind. Med., v. 31, p. 468-73, 1997.

FEUERSTEIN, M. Workstyle: definition, empirical support and implications for prevention, evaluation and rehabilitation of occupational upper extremity disorders. In: MOON, S. D.; SAUTER, S. L. (Ed.). Beyond biomechanics: psychosocial aspects of musculoskeletal disorders in office work. Bristol, PA: Taylor \& Francis, 1996. p 177-206.

GLINA, D. M. R.; ROCHA, L. E. Fatores de estresse no trabalho de operadores de centrais de atendimento telefônico de um banco em São Paulo. Rev. Bras. Med. Trabalho, v.1, p. 34-42, 2003.

HALES, T. R.; SAUTER, S. L.; PETERSON, M. R.; FINE, L. J.; PUTZ-ANDERSON, U.; SCHLEIFER, L. R.; OCHS, T. T.; BERNARD, B. P. Musculoskeletal disorders among visual display terminal users in a telecommunications 
company. Ergonomics, v. 37, n. 10, p. 1603-21, 1994.

HOESKSTRA, E.; HURRELL, J.; SWANSON, N. Evaluation of work-related musculoskeletal disorders and job stress among teleservice center representatives. Appl. Occup. Environ. Hyg., v. 10, n. 10, p. 812-7. 1995.

LAVILLE, A. Ergonomia. São Paulo: EPU, 1976.

LAZARUS, R. S.; FOLKMAN, S. Stress, appraisal and coping. New York: Springer, 1984.

LEINO, P. Symptoms of stress predict musculoskeletal disorders. J. Epidemiol. Com. Health, v. 43, p. 293-300. 1989.

MINAYO, M. C. S. O desafio do conhecimento: pesquisa qualitativa em saúde. 2 ed. São Paulo: HUCITEC; Rio de Janeiro: ABRASCO. 1993.

NIOSH. Musculoskeletal disorders and workplace factors: a critical review of epidemiologic evidence for work related musculoskeletal disorders of the neck, upper extremity and low back, chapter 7. Disponível em: http://www.cdc.gov/ niosh/ergtext7.html. 1997.

SAUTER, S. L.; SWANSON, N. G. Na ecological model of musculoskeletal disorders in Office work. In: MOON, S. D.; SAUTER, S. L. (Ed). Beyond biomechanics: psychosocial aspects of musculoskeletal disorders in Office work. Bristol: Taylor \& Francis, 1996. p 3-21.

SELYE, H. The stress of life. New York: McGraw-Hill Book Company. 1936.

SINDICATO DOS TRABALHADORES DE TELEMARKETING. Trabalho e saúde dos trabalhadores em telemarketing. São Paulo, 2001.
SMITH, M. J.; CARAYON, K. J.; SANDERS, K. J.; LIM, S. Y.; LEGRANDE, D. Employee stress and health complaints in jobs with and without electronic performance monitoring. Appl. Ergon., v. 23, p. 17-27. 1992.

SMITH, M. J.; CARAYON, P. Work organization, stress, and cumulative trauma disorders. In: MOON, S. D.; SAUTER, S. L. (Ed). Beyond biomechanics: psychosocial aspects of musculoskeletal disorders in Office work. Bristol: Taylor \& Francis, 1996. p 23-42.

SZNELWAR, E.; MASSETI. Agressões ao corpo e/ou sofrimento psíquico? Um estudo construído a partir da experiência de trabalhadores com LER/DORT. Travailler: Rev. Int. Psychopathol. Psicodinam. Travail, n.8, p. 15377. 2002.

THEORELL, T. Disorders in office work. London: Bristol Taylor Francis, 1996.

TOOMINGAS, A.; HAGMAN, M.; HANSSON, R.; ISAKSSON, I. A.; KJELLBERG, A.; NORMAN, K.; TORNQVIST, E. Working conditions and employee health at call centers in Sweden. Stockholm: National Institute for Working Life, 2001.

VASSELJEN, E.; WESTGAARD, R. H. Can stress related and neck pain develop independently of muscle activity? Pain, v. 64, p. 221-30, 1995.

WESTLANDER, G. Organizational management and theory. In: International Labour Office Encyclopaedia of Occupational Health and Safety. Geneve, International Labour Office, 1996.

WISNER, A. Por dentro do trabalho: ergonomia: método \& técnica. São Paulo: FDT-Oboré, 1987. 